\title{
Desempenho e Volatilidade dos Índices de Governança Corporativa da BM\&FBOVESPA
}

\author{
Leandro Sanches Simplicio de Oliveira ${ }^{2}$ \\ David Ferreira Lopes Santos ${ }^{3}$
}

\section{RESUMO}

Esta pesquisa teve por objetivo observar o retorno e o risco dos dois índices de Governança Corporativa (IGC e IGCT) da BM\&FBOVESPA, tendo como benchmarking o IBOVESPA no período entre 2007 e 2010 . A hipótese central assumiu que em razão das práticas de governança o IGC e IGCT apresentariam menor volatilidade e desempenho superior ao IBOVESPA. Essa proposição é suportada pelo marco teórico utilizado, onde se postula a preeminência de um sistema de gestão que verse pela transparência, fidedignidade das informações e a homogeneidade no relacionamento com os stakeholders e shareholders. Os procedimentos metodológicos utilizados foram às técnicas estatísticas descritivas de análise de posição, dispersão e correlação das séries temporais. Ademais, utilizou-se o Índice de Sharpe Ajustado para mensurar a performance (risco $\mathrm{x}$ retorno) dos índices de governança em relação ao IBOVESPA. Os resultados empíricos alinham-se as pesquisas realizadas, onde os índices de governança apresentaram menor volatilidade e melhor desempenho em relação ao IBOVESPA, contudo, essa evidência não é consistente para todo o período em análise, em especial para a crise financeira de 2008. Desta forma, o trabalho pondera que a despeito do esforço em estimular as práticas de governança corporativa, o mercado, ainda, não demonstra plena segurança nesta ação, apesar dos indícios de que no longo prazo, as empresas que utilizam esse modelo institucional apresentam performance superior.

Palavras - chave: Governança Corporativa; Volatilidade; Desempenho

\begin{abstract}
This research aimed to observe the risk and return of two indexes of Corporate Governance (IGC and IGCT) the BM\&FBOVESPA, with the benchmark IBOVESPA between 2007 and 2010. The central hypothesis assumed that in function of the governance practices and IGCT IGC had lower volatility and better performance than the IBOVESPA. This proposition is supported by the theoretical framework used, which posits the primacy of a management system that addresses transparency, consistency and reliability of the information in the relationship with stakeholders and shareholders. The methodological procedures used were the descriptive statistics analysis of position, dispersion and correlation time series. In addition, we used the Adjusted Sharpe Ratio to measure the performance (risk-return) indexes of governance in relation to IBOVESPA. The empirical results are aligned with the research carried out, where the indexes of governance had lower volatility and better performance over the IBOVESPA, however, this evidence is not consistent throughout the period under review, particularly for the 2008 financial crisis. Thus, the work reflects that despite the effort to encourage corporate governance practices, the market also does not show full security in this action, but in the long term, companies that use this institutional model show superior performance.
\end{abstract}

Keywords: Corporate Governance; Volatility; Performance

\footnotetext{
${ }^{1}$ Artigo recebido em 30.09.2011. Revisado por pares em 24.11.2011 (blind review). Recomendado para publicação em 29.11.2011 por José Ribamar Marques de Carvalho (Editor). Publicado em 01.12.2011. Organização responsável pelo periódico: UACC/CCJS/UFCG. O trabalho foi publicado nos anais do X SIAR - Simpósio Inter Institucional de Administração e Ciências Contábeis.

${ }^{2}$ Graduando em Administração de Empresas pela UNESP - Universidade Estadual Paulista no campus FCAV - Jaboticabal-SP, e-mail: 1.sanchesoliveira@gmail.com

${ }^{3}$ Doutor em Administração de Empresas pela Universidade Presbiteriana Mackenzie. Professor do Departamento de Economia Rural da FCAV - Jaboticabal-SP - UNESP, e-mail: david.lopes@ fcav.unesp.br
}

REUNIR - Revista de Administração, Contabilidade e Sustentabilidade - Vol. 1, n ${ }^{\circ}$ 2, p.52-64, Set-Dez/2011. 


\section{INTRODUÇÃO}

No curso do tempo, desde o advento dos mercados de capitais e principalmente, da criação da grande empresa americana, observa-se um esforço em entregar legitimidade as informações disponibilizadas pelas empresas e a própria eficiência dos mercados onde os papéis são transacionados (ROSSONI; SILVA, 2010). Esta demanda tem ocupado atualmente um eixo central na formação dos executivos e se constituído item permanente de pauta de pesquisas acadêmicas e discussões empresariais, principalmente com os escândalos empresariais que marcaram a primeira década deste século (ANDRADE; ROSSETI, 2004).

Nessa esteira, a Bolsa de Mercadorias e Futuros de São Paulo (BM\&FBOVESPA) criou os níveis 1, 2 e o Novo Mercado, como forma de estratificar e diferenciar as empresas que assumem padrões elevados de compromisso com os acionistas e demais grupos de interesse. A expectativa é que a empresa, ao ingressar em um desses níveis conquiste melhor imagem perante a sociedade e, principalmente, um lugar de destaque no mercado de capitais (CARVALHO, 2003).

Esses níveis se distinguem pela quantidade de exigências a serem cumpridas pelas empresas, e tem como principal objetivo a redução da assimetria informacional existente no mercado financeiro (PINHEIRO, 2005).

Segundo Oliveira (2006), com a inserção da empresa em algum nível de GC da BM\&FBOVESPA e a conseqüente redução da assimetria informacional existente no mercado, a empresa, através desta prática, gera uma maior segurança e transparência das informações para seus clientes, fornecedores e acionistas, o que resulta em maior liquidez e valorização do preço das ações.

Não obstante, a BM\&FBOVESPA criou os índices IGC e IGCT (Índice de Ações com Governança Corporativa Diferenciada e o Índice de Governança Trade, respectivamente). Esses índices compõem uma carteira teórica de ações, onde o primeiro congrega as empresas que participam dos três níveis de governança da bolsa e o segundo é mais restrito para aquelas empresas com alta liquidez nas suas ações (BM\&FBOVESPA, 2011).

É neste contexto que se posiciona esta pesquisa, cuja motivação principal se encerra na seguinte questão: Existe diferença ao nível de desempenho e volatilidade entre os índices de governança corporativa do mercado de capitais do Brasil e o IBOVESPA?

Ressalta-se que a utilização do IBOVESPA enquanto benchmarking para comparação de ativos mobiliários é ponto pacífico na literatura e no bojo empresarial.

Postulou-se como objetivo para atendimento a motivação norteadora deste trabalho as seguintes ações:

$\checkmark$ Analisar a volatilidade e o desempenho individual e inter-relacional dos três índices.

$\checkmark$ Discutir os resultados empíricos com demais pesquisas realizadas no Brasil.

A análise proposta tem como escopo, comparar a volatilidade e o desempenho dos índices diariamente durante os anos de 2007, 2008, 2009 e 2010, cujo período foi escolhido devido a possibilidade de utilizar a crise financeira de 2008 como referencial, ou seja, tem-se três momentos: pré, durante e pós crise.

No interesse em melhor organizar a estrutura dessa pesquisa, apresenta-se o referencial teórico que fundamenta a hipótese central deste trabalho e justifica a metodologia utilizada. $\mathrm{Na}$ sequencia os procedimentos metodológicos adotados são demonstrados, a fim de permitir

REUNIR - Revista de Administração, Contabilidade e Sustentabilidade - Vol. 1, nº 2, p.52-64, Set-Dez/2011. 
o melhor entendimento dos resultados, bem como replicações em pesquisas futuras. Os resultados são discutidos na quarta seção que traz posteriormente as conclusões da pesquisa, além de novos horizontes de investigação nesse tema. As referências bibliográficas encerram o artigo.

\section{FUNDAMENTAÇÃO TEÓRICA}

A prática de governança corporativa está na esfera institucional da firma e, portanto, congrega o plano estratégico desta, tomando como o foco o relacionamento com o público de interesse (acionistas e demais interessados) (DAVIS, 2005, apud ROSSONI e SILVA, 2010). Destaca-se ainda, que enquanto prática institucional a governança corporativa vem a minimizar os problemas decorrentes da Teoria de Agência e da Teoria de Custos de Transação, cujas premissas teóricas foram formuladas ainda na década de 70 do último século (OKIMURA, 2003), (ROGERS, 2006), (ROSSONI e SILVA, 2010).

Assim, desde a estrutura da empresa tradicional weberiana onde se postulava a separação do patrimônio e gestão, pode-se afirmar que as empresas passaram a demandar práticas de governança, no entanto, os efeitos das assimetrias informacionais ganharam mais representatividade com o crescimento das organizações, a pulverização do patrimônio, o desenvolvimento dos mercados de capitais, a diversificação societária e as inovações dos mecanismos de financiamento (OKIMURA, 2003), (SILVEIRA, BARROS e FAMÁ, 2003), (ROGERS, 2006).

Por isso, tem-se "quase" como consenso a concordância acadêmica e empresarial quanto a necessidade de aprimoramento de práticas de governança corporativa, cujo conceito, assume-se aqui, o proposto pelo Instituto Brasileiro de Governança Corporativa (IBGC) "Sistema pelo qual as organizações são dirigidas, monitoradas e incentivadas, envolvendo os relacionamentos entre proprietários, conselho de administração, diretoria e órgãos de controle" (IBGC, 2009, apud ROSSONI e SILVA, 2010).

Como uma forma de estímulo ao mercado de capitais brasileiro, em 26 de junho de 2001 iniciou-se o novo pregão de Governança Corporativa da BOVESPA, o qual foi inspirado em experiências externas de promoção dos mercados de capitais, como o da Bolsa de Frankfurt "Neuer Market" (NASCIMENTO, 2003, p. 52).

A despeito da coerência do discurso diversos estudos têm sido empreendidos no intuito de analisar os resultados da prática de governança corporativa. No aspecto financeiro Okimura (2003) destaca os trabalhos de Monsen et. al (1968) e Karmeshen (1968) como seminais no estudo de formas/estrutura de controle e desempenho, de forma que nos últimos 20 anos múltiplas pesquisas foram realizadas para verificar os efeitos das práticas de governança no desempenho ou no risco das empresas ou índices, porém com resultados diversos (VIEIRA; MENDES, 2006).

Para fins de delineamento de escopo, optou-se por tomar os trabalhos empíricos no Brasil listados na Tabela 1: 
Tabela 1 - Pesquisas empíricas selecionadas como parâmetro

\begin{tabular}{|c|c|c|c|c|}
\hline Autores & Amostra & Período & Metodologia & Resultados \\
\hline $\begin{array}{c}\text { Vieira e Mendes } \\
\qquad(2006)\end{array}$ & $\begin{array}{l}\text { IGC; IBR-X 100; } \\
\text { IBR-X 50. }\end{array}$ & 2001 a 2004 & $\begin{array}{l}\text { Estatística } \\
\text { descritiva }\end{array}$ & $\begin{array}{lr}\text { Superioridade } & \text { de } \\
\text { performance } & \text { e } \\
\text { volatilidade } & \text { das } \\
\text { empresas } & \text { com } \\
\text { práticas } & \\
\text { governança. } & \\
\end{array}$ \\
\hline $\begin{array}{l}\text { Silveira, Barros e } \\
\text { Famá (2003) }\end{array}$ & $\begin{array}{l}\text { Empresas com } \\
\text { Capital Aberto }\end{array}$ & 1998 a 2000 & Regressão Múltipla & $\begin{array}{l}\text { Tamanho do } \\
\text { conselho influencia } \\
\text { no desempenho } \\
\text { financeiro das } \\
\text { empresas }\end{array}$ \\
\hline $\begin{array}{l}\text { Rogers, Ribeiro e } \\
\text { Sousa }(2005)\end{array}$ & $\begin{array}{l}\text { IGC; IBR-X; IBR- } \\
\text { X 50; IBOVESPA; } \\
\text { FGV-E; FGV-100 }\end{array}$ & 2001 a 2005 & $\begin{array}{l}\text { Bootstrap com } \\
\text { Índice de Sharpe, } \\
\text { Treynor, M2, Alfa } \\
\text { de Jensen e } \\
\text { Appraisal Ratio }\end{array}$ & $\begin{array}{l}\text { Pouca diferença } \\
\text { estatística entre os } \\
\text { índices, porém o } \\
\text { IGC apresentou } \\
\text { melhor } \\
\text { performance. }\end{array}$ \\
\hline $\begin{array}{l}\text { Macedo, Mello e } \\
\text { Tavares Filho } \\
\text { (2006) }\end{array}$ & $\begin{array}{c}\text { Empresas que } \\
\text { aderiram ao N1 da } \\
\text { Bovespa }\end{array}$ & 2001 a 2003 & Teste-t e Wilcoxon & $\begin{array}{l}\text { Não foi encontrada } \\
\text { evidência de } \\
\text { melhoria em } \\
\text { performance e risco } \\
\text { para as adotantes do } \\
\text { N1 }\end{array}$ \\
\hline Silva e Leal (2005) & Empresas do IGC & 1998 a 2002 & Dados em Painel & $\begin{array}{l}\text { Empresas com } \\
\text { práticas de } \\
\text { governança } \\
\text { possuem resultados } \\
\text { maiores que a } \\
\text { média e elevado Q- } \\
\text { Tobin }\end{array}$ \\
\hline
\end{tabular}

Fonte: Elaborado pelos autores.

Os resultados das pesquisas acima retratam a diversidade de amostra, resultado e forma em que os estudos são realizados, de toda forma, todas procuram avaliar o impacto no desempenho e exceção a pesquisa de Silva e Leal (2005), todas as outras os resultados estatísticos não foram expressivos, apesar de sinalizarem quanto a importância das práticas de governança.

Enquanto método esse trabalho se aproxima de Vieira e Mendes (2006) cujos resultados sinalizam para uma superioridade das empresas com boa governança corporativa. Os autores afirmam que o mercado estaria disposto a pagar um "prêmio de governança" sobre o preço das ações, o que está estreitamente ligado ao menor risco de crédito associado e essas empresas. Segundo os autores, a governança corporativa proporciona aos credores maior credibilidade nos resultados da empresa e os acionistas tornam-se mais propensos a investir, uma vez que o risco de manipulações por grupos específicos é reduzido. O resultado é que, para qualquer mercado em crescimento, as práticas de boa governança são fundamentais.

Outro estudo destacado é o de Rogers, Ribeiro e Sousa (2006), cujo trabalho estuda comparativamente diferentes índices com o IGC onde inicialmente são realizadas medidas de posição e dispersão e depois testados os indicadores de performance (Sharpe, Treynor, etc). Os resultados apresentaram alta correlação entre os índices, porém com o IGC assumindo um desempenho superior aos demais. 
Em decorrência dos estudos apresentados e do aparato conceitual que suporta o tema de governança corporativa, tomou-se como hipóteses para este trabalho:

$H_{1}$ : O IGCT deve apresentar retornos médios superiores ao ICG e este deve apresentar retornos médios superiores ao IBOVESPA.

$\mathrm{H}_{2}$ : $\mathrm{O}$ IGCT deve apresentar menor volatilidade que o IGC e este menor que o IBOVESPA.

$H_{3}: \mathrm{O} I G C T$ deve apresentar melhor performance que o IGC e este deve apresentar um desempenho superior ao IBOVESPA.

\section{PROCEDIMENTOS METODOLÓGICOS}

Em face da questão motivadora dessa pesquisa, optou-se por uma investigação descritiva de natureza quantitativa com base em procedimentos estatísticos básicos. Observase, contudo, que utilização das medidas de posição, dispersão e correlação tradicionais podem auxiliar numa observação longitudinal de forma objetiva e simples. Não obstante, os trabalhos de Vieira e Mendes (2006) e Rogers, Ribeiro e Sousa (2005) também o fazem. Reforça-se, portanto, o caráter descritivo da pesquisa, sua potencialidade e utilização nesta área do conhecimento.

As amostras são os resultados diários dos índices IBOV, IGC, IGCT coletados entre os anos de 2007 a 2010. Os dados foram levantados através do site da BM\&FBOVESPA (www.bmfbovespa.com) e tabulados e tratados em planilhas eletrônicas.

A finalidade do IBOV é servir como indicador médio do comportamento do mercado. Devido a isso, a carteira do índice corresponde a $80 \%$ do número de negócios e do volume financeiro verificados no mercado à vista. Além disto, o IBOV possui $70 \%$ da capitalização bursátil de todas as empresas com ações negociadas na BM \& FBOVESPA.

O IGC - Índice de Ações com Governança Corporativa Diferenciada tem por objetivo medir o desempenho de uma carteira teórica composta por ações de empresas que apresentem bons níveis de governança corporativa. Tais empresas devem ser negociadas no Novo Mercado ou estar classificadas nos Níveis 1 ou 2 da BOVESPA e entram para a carteira do índice no dia de adesão a um dos níveis.

A terceira e última variável a ser estudada será o IGCT (Índice de Governança Corporativa Trade), criado com base no IGC. Para simplificar, as ações que participam do IGCT são as ações do IGC que atendem simultaneamente aos seguintes critérios de liquidez: inclusão em uma relação de ações cujos índices de negociabilidade somados representem 99\% do valor acumulado de todos os índices individuais; e participação em termos de presença em pregão igual ou superior a $95 \%$ no período.

Os retornos diários foram calculados de forma percentual para os três índices conforme fórmula abaixo:

$$
\bar{R}=\frac{P_{t+1}-P_{t}}{P_{t}}
$$

Quanto às medidas de dispersão, optou-se pelo uso tradicional do desvio padrão em razão do seu largo uso em Finanças como forma de mensurar risco e ser utilizado no cálculo do Índice Sharpe. Em conformidade com Costa Neto (2002) tem-se uma medida capaz de aferir o quanto os dados estão dispersos da região central. 


$$
\sigma=\sqrt{\frac{\sum_{i=1}^{n}\left(P_{i}-\bar{P}\right)^{2}}{n-1}}
$$

Outra medida estatística utilizada no trabalho foi o coeficiente de correlação linear de Pearson, que indica a tendência da variação conjunta de duas variáveis consideradas (COSTA e NETO, 2002). A vantagem de utilizar do coeficiente de correlação é que este é adimensional, isto é, pode variar entre -1 e +1 , o que não ocorre, por exemplo com a covariância.

(04) Coeficiente de Correlação Linear de Pearson $=r_{X, Y}=\frac{\operatorname{Cov}(X, Y)}{\sigma_{X} \cdot \sigma_{Y}}$

O indicador de desempenho utilizado para congregar a relação risco versus retorno de forma comparada entre os índices é o Índice de Sharpe, criado por William F. Sharpe em 1966. É um indicador que representa a relação entre o prêmio pago pelo risco assumido e o risco do investimento. Indica-nos, portanto, o prêmio oferecido por um ativo para cada percentual adicional de risco assumido (VARGA, 1999). Quanto maior é o índice, melhor é o desempenho da carteira.

$$
I S=\frac{(R F-R L R)}{\sigma_{R F}}
$$

Onde:

$\mathrm{RF}=$ Retorno do Fundo

RLR $=$ Retorno Livre de Risco

DP $=$ Desvio Padrão do Retorno do Fundo

\section{APRESENTAÇÃO E DISCUSSÃO DOS RESULTADOS}

Os resultados alcançados na pesquisa foram separados em três etapas no interesse em facilitar a análise e as discussões que procuram encontrar os objetivos e motivação deste trabalho. Além disso, os resultados anuais foram consolidados em gráficos únicos, afim de facilitar a análise longitudinal dos índices.

No final procura-se consolidar as principais verificações observadas no trabalho e relações com a teoria que sustentou essa pesquisa.

\subsection{Retorno}

O Gráfico 1 apresenta de forma comparada a tendência dos três índices ao longo dos anos em relação ao retorno, conforme a fórmula 1. Percebe-se que não há uma predominância de um índice sobre o outro ao longo do tempo, além destes terem evoluídos sempre no mesmo sentido, positivo ou negativo, e na mesma proporção durante o período de 2007 a 2010.

REUNIR - Revista de Administração, Contabilidade e Sustentabilidade - Vol. 1, nº 2, p.52-64, Set-Dez/2011. 


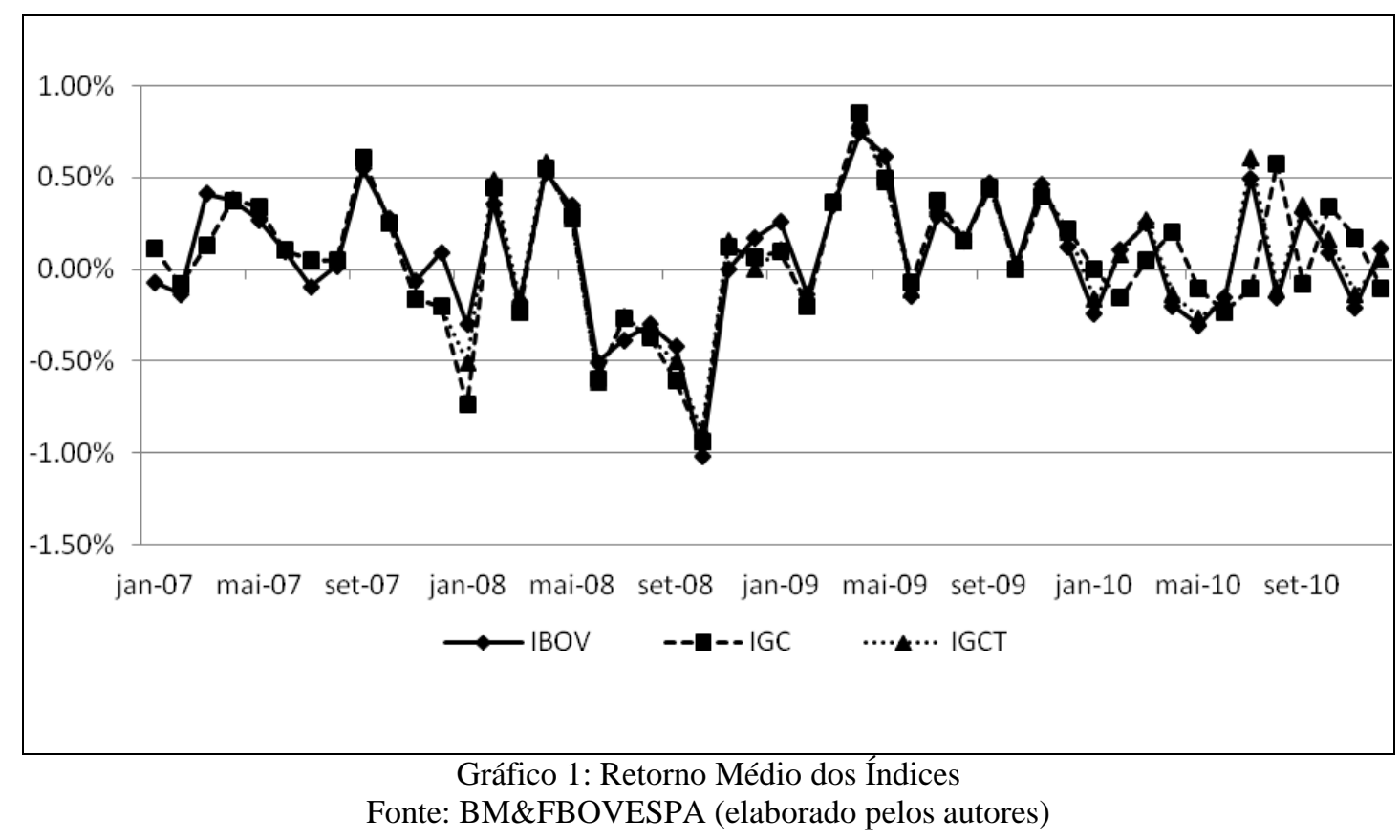

Sabe-se que em 2007, em especial até o fim de julho, a economia mundial atravessava um dos períodos de maior prosperidade dos últimos trinta anos, as empresas estavam lucrando muito, a China crescia a $10 \%$ ao ano e o Brasil exportava matéria-prima em volumes e preços recordes. A partir de julho de 2007 as bolsas começaram a operar em certa instabilidade até a crise imobiliária americana atingir o mundo em meados de 2008. No ano 2009 a economia passa por um período de recuperação o qual em abril o retorno médio da BM\&FBOVESPA ultrapassa o retorno dos títulos públicos atrelados à SELIC. Em 2010 a bolsa se manteve de lado, com receio de qualquer evento que pudesse ocorrer no globo.

Essa abordagem macroeconômica pode ser percebida na Tabela 2 onde são acumulados os retornos dos três índices no período em análise.

Tabela 2 - Retorno Acumulado dos Índices

\begin{tabular}{|c|c|c|c|c|c|}
\hline Índices & $\mathbf{2 0 0 7}$ & $\mathbf{2 0 0 8}$ & $\mathbf{2 0 0 9}$ & $\mathbf{2 0 1 0}$ & Total \\
\hline IBOVESPA & $39,90 \%$ & $-39,62 \%$ & $65,88 \%$ & $3,07 \%$ & $69,23 \%$ \\
\hline IGC & $29,41 \%$ & $-51,58 \%$ & $64,62 \%$ & $13,57 \%$ & $56,02 \%$ \\
\hline IGCT & $33,47 \%$ & $-41,38 \%$ & $63,05 \%$ & $12,14 \%$ & $67,28 \%$ \\
\hline \multicolumn{5}{|c}{ Fonte: BM\&FBOVESPA (elaborado pelos autores) }
\end{tabular}

A partir da associação do Gráfico 1 com a Tabela 2 deve-se rejeitar parcialmente a hipótese 1, pois o IBOVESPA apresentou melhores resultados nos três primeiros anos analisados e no total acumulado. Todavia, o IGCT apresentou melhores resultados que o IGC, conforme era esperado e o retorno acumulado ficou próximo do IBOVESPA.

Desta forma, para o período analisado, as empresas com práticas de governança corporativa obtiveram valorização dos seus papéis inferiores àquelas que não possuem. 


\subsection{Volatilidade}

A pesquisa, também, analisou os riscos intrínsecos de cada carteira de índice através do desvio padrão dos seus retornos. Pode-se notar no Gráfico 2 que nos períodos adversos como na crise financeira de outubro de 2008 e com o eminente risco de default da Grécia em maio de 2010 ambos os índices tiveram um aumento da volatilidade.

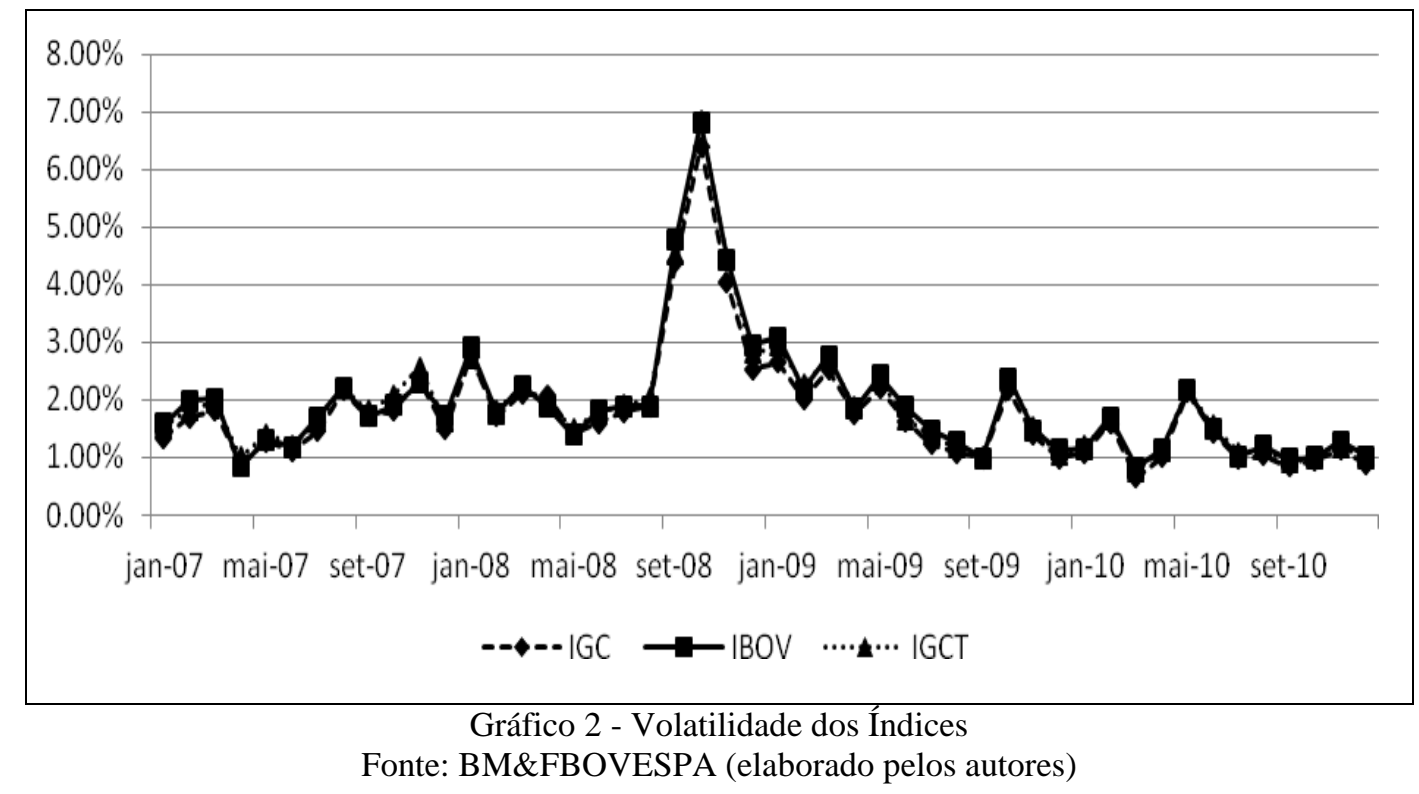

Não houve uma diferença gráfica significativa nas volatilidades entre os índices, o que de certa forma não era esperado nessa pesquisa. Sendo assim, providenciou-se a Tabela 3 com a volatilidade anual desses índices calculados a partir do produto do desvio padrão médio diário de cada índice com a raiz quadrada do ano útil da bolsa (252 dias). Essa técnica foi utilizada no intuito de captar melhor a volatilidade dos índices de forma absoluta.

Tabela 3 - Volatilidade Anual dos Índices

\begin{tabular}{|l|c|r|r|r|c|}
\hline \multicolumn{1}{|c|}{ Índices } & $\mathbf{2 0 0 7}$ & $\mathbf{2 0 0 8}$ & $\mathbf{2 0 0 9}$ & $\mathbf{2 0 1 0}$ & Média \\
\hline IBOVESPA & $27,07 \%$ & $45,99 \%$ & $30,21 \%$ & $19,76 \%$ & $30,76 \%$ \\
\hline IGC & $25,31 \%$ & $43,32 \%$ & $27,25 \%$ & $18,17 \%$ & $28,51 \%$ \\
\hline IGCT & $27,77 \%$ & $45,74 \%$ & $29,52 \%$ & $19,53 \%$ & $30,64 \%$ \\
\hline \multicolumn{5}{|c}{ Fonte: BM\&FBOVESPA (elaborado pelos autores) }
\end{tabular}

Observa-se que o IGC foi inferior ao IBOVESPA em todos os períodos, contudo o IGCT foi superior ao IGC em todos os períodos e superior ao IBOVESPA em 2007, mantendo uma volatilidade anual média muito próxima do IBOVESPA. Desta forma, rejeitase, também, parcialmente a hipótese 2, porém destaca-se que de fato as empresas com práticas de governança corporativa apresentam uma volatilidade inferior aquelas que não o fazem, para o período analisado essa diferença foi de $7,89 \%$ na média.

Além da volatilidade aferida pelo desvio padrão, propôs-se neste trabalho verificar o grau de correlação entre os índices, na expectativa de que os índices de governança se distanciassem do IBOVESPA, ou seja, apresentassem baixos graus de correlação.

REUNIR - Revista de Administração, Contabilidade e Sustentabilidade - Vol. 1, nº 2, p.52-64, Set-Dez/2011. 
O Gráfico 3 apresenta os coeficientes de correlação em percentual, dado que este é uma medida adimensional para o período analisado.

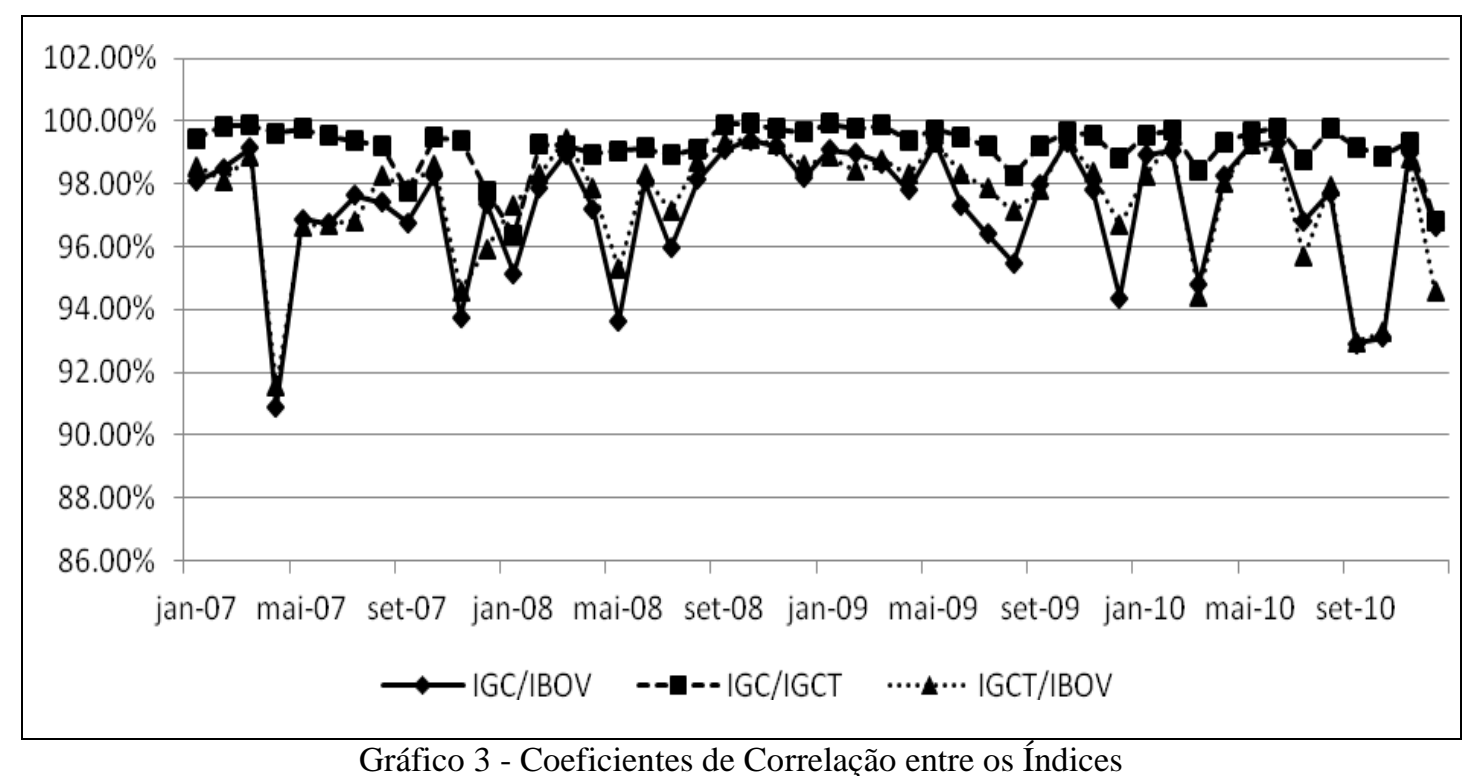

Fonte: BM\&FBOVESPA (elaborado pelos autores)

Percebe-se uma grande aderência entre os índices, mostrando que tanto retorno como volatilidade tiveram um desempenho no mesmo sentido. Por outro modo, o Gráfico 3 confirma as tendências observadas nos Gráficos 1 e 2, ou seja, os índices são altamente correlacionados, sendo que para o período, os coeficientes foram sempre superiores a $90 \%$.

De forma consolidada o IGC e o IGCT tiveram em média 99,22 \% de correlação no período, o que mostra a grande aderência entre os dois. Quando comparados com o IBOVESPA, a correlação média com o IGC ficou em 97,30\% contra 97,55\% do IGCT o que confirma a rejeição parcial da hipótese 2 , dado que a lógica teórica proposta seria uma menor correlação deste último com o IBOVESPA.

\subsection{Retorno ajustado ao risco}

O Índice Sharpe Ajustado no caso do trabalho foi utilizado para medir o retorno sobre o risco do IGC e do IGCT em relação ao benchmark IBOVESPA. Optou-se por utilizar o Índice de Sharpe Ajusta, pois em 2008 e 2010 o retorno do IBOVESPA foi inferior a taxa livre de risco, considerando a SELIC como tal. Não obstante, como o foco o do trabalho é a comparação dos índices de governança com o IBOVESPA, não houve prejuízo no uso do índice de Sharpe ajustado, ressalta-se, ainda que tal prática é largamente utilizada na literatura e meio empresarial (VARGAS, 1999).

O Gráfico 4 apresenta os resultados do ISA para os dois índices de governança. De modo, que este procedimento congrega os resultados anteriores analisados de forma isolada (volatilidade e retorno). Desta forma, a proposta é verificar se de fato empresas com práticas de governança apresentam melhor performance (risco versus retorno) que aquelas que não o fazem. 


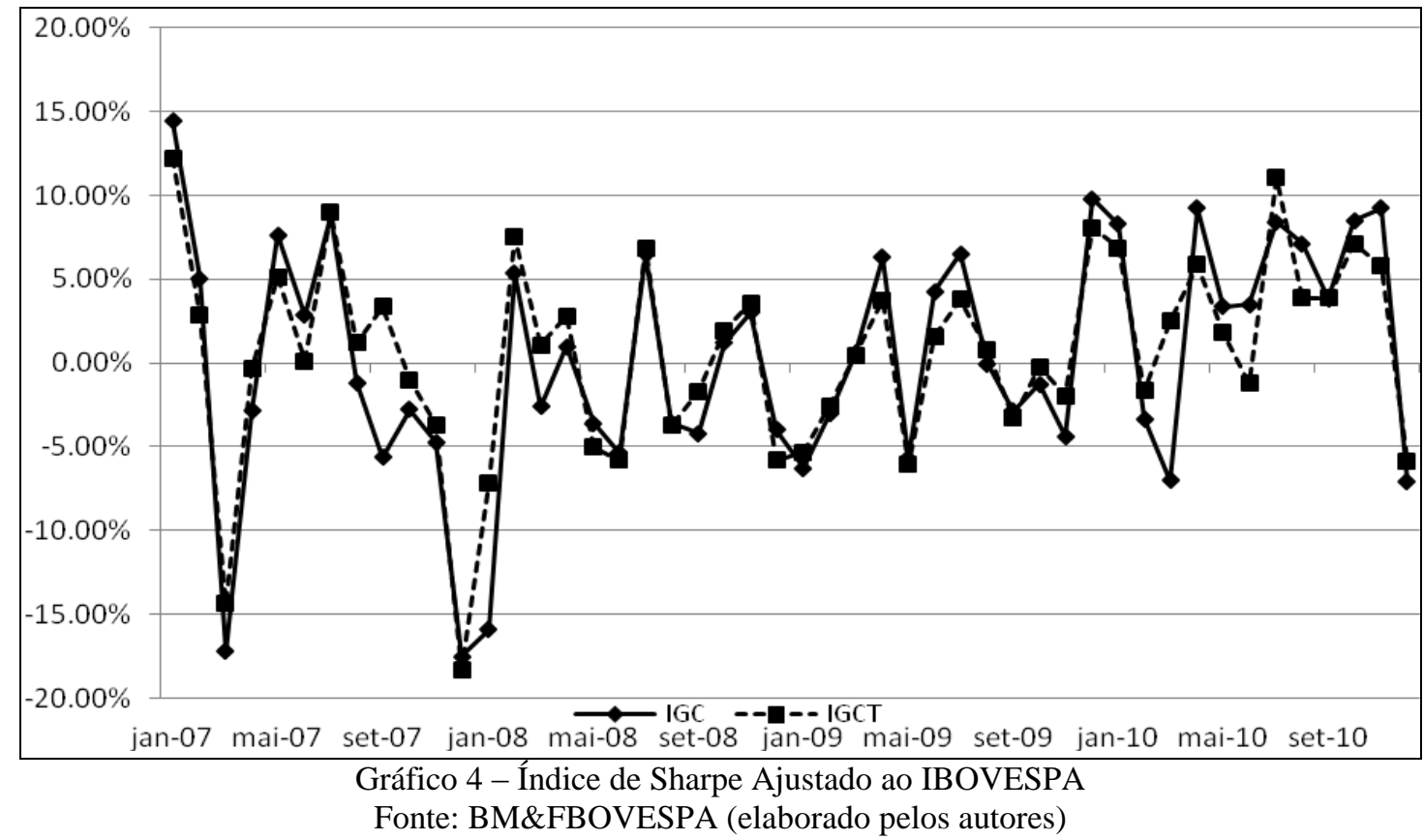

O Gráfico 4 retrata a dificuldade em assegurar a melhor performance dos índices de governança frente ao IBOVESPA, percebe-se, inclusive que as variações negativas são mais profundas que as positivas.

Verifica-se que o IGC e IGCT em praticamente $50 \%$ dos casos teve um retorno sobre uma unidade de risco acima do IBOVESPA, e na outra metade do período manteve-se abaixo. Entretanto, na média do período, o IGC apresentou um retorno maior que o IBOV tomando como base cada unidade de risco. Este fato pode ser melhor analisado na Tabela 4.

Tabela 4 - Desempenho Ajustado dos Índices de Governança

\begin{tabular}{|c|c|c|c|c|c|}
\hline Índices & $\mathbf{2 0 0 7}$ & $\mathbf{2 0 0 8}$ & $\mathbf{2 0 0 9}$ & $\mathbf{2 0 1 0}$ & Total \\
\hline IGC & $-13,20 \%$ & $-22,36 \%$ & $3,87 \%$ & $44,00 \%$ & $12,31 \%$ \\
\hline IGCT & $-3,86 \%$ & $-5,54 \%$ & $-1,11 \%$ & $40,00 \%$ & $29,48 \%$ \\
\hline
\end{tabular}

Fonte: BM\&FBOVESPA (elaborado pelos autores)

Nota-se que no total do período analisado os índices de governança foram superiores ao IBOVESPA, contudo, muito influenciados pelo resultado de 2010, quando a volatilidade destes foi menor que o benchmarking e o retorno melhor. Todavia, os dois primeiros anos (pré e durante a crise o ISA foi negativo para os dois índices de governança e no ano de 2008 o desempenho foi muito abaixo do IBOVESPA.

Desta forma, tomando como base o resultado do período, aceita-se a hipótese 3 parcialmente a hipótese 3, pois o IGCT apresentou uma performance melhor que o IGC e este melhor que o IBOVESPA. Contudo, ressalta-se que este desempenho não foi consistente ao longo do período e que justamente no período de crise, os índices de governança não se mostraram robustos em comparação com o IBOVESPA.

Os resultados alcançados nesta pesquisa coadunuam com pesquisas empíricas utilizadas como contorno para este trabalho, em especial Rogers, Medeiros e Sousa (2006).

Na pesquisa de Rogers, Medeiros e Sousa (2005) o retorno acumulado do IGC foi maior que o IBOVESPA, o que não ocorreu nessa pesquisa, por outro lado, o risco na 
pesquisa dos autores do IGC também foi inferior ao IBOVESPA e a performance utilizando o Índice de Sharpe Ajustado foi melhor. Desta forma, esta pesquisa corrobora em grande parte a pesquisa realizada pelos autores em referência.

Pondera-se aqui que as dificuldades encontradas pelos autores em entregar maior significância estatística para os seus resultados devem-se a falta de consistência dos índices de governança frente o IBOVESPA ou outro índice de mercado. Esse fato foi observado na nossa pesquisa, onde o desempenho superior dos índices de governança só foi alcançado no ano de 2010, assim, discorda-se aqui de que o mercado estaria disposto a pagar um prêmio pela governança, conforme sugere Vieira e Mendes (2006).

Apregoamos com base nos resultados desta pesquisa que o mercado ainda está amadurecendo quanto à importância e efetividade das práticas de governança corporativa.

\section{CONSIDERAÇÕES FINAIS}

O Brasil tem empreendido vários esforços com o intuito de melhorar os padrões de governança corporativa, tais como: a instituição da Lei 10.303/2001 - reforma da Lei das Sociedades Anônimas, a disseminação de códigos de boas práticas de governança corporativa e a instauração do Novo Mercado em 2001 e de Níveis Diferenciados de Governança Corporativa pela Bovespa (auto-regulação).

Apesar do esforço em melhorar a transparência nas empresas na tentativa de aumentar a transferência de poupança para o mercado de capitais, nossa bolsa ainda esta bem atrás de países desenvolvidos. Mesmo em constantes melhoras, o mercado de capitais sempre esteve à margem do arranjo financeiro nacional, permanecendo como características desse mercado: baixa capitalização bursátil; inexpressivo volume transacionado; poucas emissões primárias; reduzido número de companhias abertas; alta concentração das transações em poucas ações; e baixa liquidez.

Nessa esteira, diversas pesquisas têm sido realizadas no interesse em avaliar como essa nova variável interna à firma (Modelo de Governança Corporativa) influencia no desempenho dos títulos mobiliários das empresas que a adotam, em especial, no comportamento da sua fração acionária. Observou-se nos fundamentos teóricos, que a prática organizacional de governança corporativa é antiga e vem se desenvolvendo e consolidando no curso do tempo, com destaque para os momentos em que escândalos de controle internos assumem as chamadas da mídia.

Por isso, esse trabalho procurou, a partir, de outras pesquisas empíricas realizadas para a realidade brasileira analisar os índices IGC e IGCT que formam uma carteira teórica com as ações das empresas com práticas diferenciadas de governança, onde a expectativa central era verificar se esses índices apresentariam desempenho (risco $\mathrm{x}$ retorno) superior que o IBOVESPA.

Os resultados empíricos não confirmaram as três hipóteses na sua totalidade, pois para o período analisado os índices de governança apresentaram oscilações frente o IBOVESPA onde a menor volatilidade verificada e o melhor desempenho só foram percebidos quando se considerou o valor final, fortemente influenciado pelos resultados de 2010.

Além disso, o IGCT que compõem as ações do IGC com maior liquidez apresentaram foram mais voláteis que o IGC. Inobstante, o Índice de Sharpe Ajustado foi importante e robusto suficiente para congregar os resultados analíticos desenvolvidos e demonstrar que no acumulado do período os índices de governança foram superiores ao IBOVESPA, porém com

REUNIR - Revista de Administração, Contabilidade e Sustentabilidade - Vol. 1, nº 2, p.52-64, Set-Dez/2011. 
a confirmação do baixo desempenho destes em dois períodos específicos 2007 e 2008, sendo este último o auge da crise financeira.

Os procedimentos metodológicos mostraram-se ajustados para o interesse da pesquisa e demonstraram por outro modo, os mesmos resultados e limitações que as técnicas multivariadas empreendidas por outros trabalhos.

Dentre, as múltiplas oportunidades de pesquisa, aponta-se como uma possibilidade de investigação a comparação não entre índices, mas entre empresas do mesmo setor, além da análise do beta destas empresas.

\section{REFERÊNCIAS}

ANDRADE, Adriana; ROSSETI, José Paschoal. Governança Corporativa: fundamentos, desenvolvimento e tendências. São Paulo: Atlas, 2004.

CARVALHO, Antônio Gledson de. Ascensão e Declínio do Mercado de Capitais no Brasil: A Experiência dos Anos 90. Programa de Seminário Acadêmico, Seminário 25/00, Brasília, 2003.

COSTA NETO, P. L. O. Estátistica. 2. ed. São Paulo: Editora Edgard Blücher, 2002.

SILVA, A. C.; LEAL, R. P. C. Corporate Governance Index, Firm Valuation and Performance in Brazil. Revista Brasileira de Finanças, Rio de Janeiro, v. 3, n. 1, 2005, pp. p. 1-18.

MACEDO, F. Q.; MELLO, G. R.; TAVARES FILHO, F. Adesão ao nível 1 de governança corporativa da Bovespa e a percepção de risco e retorno das ações pelo mercado. In: $6^{\circ}$ Congresso USP de Controladoria e Contabilidade, 2006, São Paulo. Congresso USP de Controladoria e Contabilidade, 2006.

OKIMURA, R. T. Estrutura de propriedade, governança corporativa, valor e desempenho das empresas no Brasil. Dissertação (Mestrado em Administração) - FEA/USP, São Paulo, 2003, p. 120.

PINHEIRO, Lima Juliano. Mercado de Capitais. 3. ed. São Paulo: Atlas, 2005.

ROGERS, P. Governança Corporativa, mercado de capitais e crescimento econômico no Brasil. Dissertação (Mestrado em Administração) - Universidade Federal de Uberlândia, 2006, p. 146.

ROGERS, Pablo ; RIBEIRO, K. C. S.; SOUSA, A. F. Comparações Múltiplas das Carteiras de Bolsa no Brasil: Avaliação da Performance do Índice de Governança Corporativa. REGE. Revista de Gestão USP, São Paulo, v. 12, n. 4, $4^{\circ}$ Trim, 2005, pp. 53-70,.

ROSSONI, Luciano ; SILVA, C. L. M. da. Institucionalismo Organizacional e Práticas de Governança Corporativa. RAC. Revista de Administração Contemporânea (Impresso), v. 14, 2010, pp. 173-198.

REUNIR - Revista de Administração, Contabilidade e Sustentabilidade - Vol. 1, nº 2, p.52-64, Set-Dez/2011. 
OLIVEIRA, L. S. S. de; SANTOS, D. F. L. Desempenho e Volatilidade dos Índices...

SILVEIRA, A. M.; BARROS, L. A. B. C.; FAMÁ, R. Estrutura de Governança e Valor das Companhias Abertas Brasileiras. RAE. Revista de Administração de Empresas, v. 43, n. 3, 2003, pp. 50-64.

VARGA, G. Índice de Sharpe e outros indicadores de performance aplicados a fundos de ações brasileiros. Revista de Administração Contemporanea, 1999.

VIEIRA. S. P.; MENDES A. G. S. T. Governança corporativa: uma análise de sua evolução e impactos no mercado de capitais brasileiro. Organizações em Contexto, v.2,n.4, junho 2006, pp.48-67. 